\title{
Diversidade, redundância e competência distribuída em um sistema virtual de aprendizagem colaborativa
}

\section{Diversity, Redundancy and Distributed Competence in a Virtual System of Collaborative Learning}

\author{
Valdir Silva* \\ Universidade do Estado de Mato Grosso \\ Cáceres - Mato Grosso / Brasil
}

\begin{abstract}
RESUMO: O trabalho proposto discute o conceito de aprendizagem colaborativa, tomando como ponto de partida o conceito de Zona de Desenvolvimento Proximal (ZDP), formulado por Vygotsky (1978). Por entender que o processo de colaboração em um sistema de aprendizagem se faz em uma perspectiva para além da descrita para a ZDP., defendo o conceito de competências distribuídas que se realizam dentro de um sistema altamente complexo, marcado pela emergência de atitudes colaborativas em decorrência da diversidade (HOLLAND, 1995; VAN LIER, 2004) e da capacidade de redundância (DAVID e SUMARA; 2006) que caracterizam os sistemas sociais. Para mostrar essa dinâmica, tomo para análise, 1.370 e-mails intercambiados pelos participantes (professor e alunos) de uma comunidade virtual de aprendizagem. A análise permitiu verificar que o processo de colaboração se configurou em uma propriedade dinamizadora da comunidade, ou seja, um evento que emergia nos interstícios entre o previsível e o imprevisível do sistema. As práticas colaborativas entre os participantes do sistema estudado configuraram uma propriedade do sistema, pois, através delas o sistema estudado se revelou ainda mais dinâmico e complexo.
\end{abstract}

PALAVRAS-CHAVE: sistema; colaboração; competência distribuída.

ABSTRACT: The paper discusses the concept of collaborative learning, taking as its starting point the concept of Zone of Proximal Development (ZPD), formulated by Vygotsky (1978). Understanding that the process of collaboration in a learning system is done in a perspective beyond the one described for the

\footnotetext{
*ollule4@yahoo.com
} 
ZPD, I defend the concept of distributed competence within a highly complex system marked by the emergence of collaborative attitudes due to the diversity (HOLLAND, 1995; VAN LIER, 2004) and power redundancy (DAVID; SUMARA, 2006) characterizing social systems. To show that dynamics, I analyzed 1,370 e-mails exchanged by the participants (teacher and students) of a virtual learning community. The analysis showed that the collaborative process was configured in a proactive community property, i.e., an event that emerged in the interstices between the predictable and the unpredictable of the system. The collaborative practices among participants of the studied system constituted a system property, because through them it showed to be even more dynamic and complex.

KEYWORDS: system; collaboration; distributed competence.

\section{O papel do outro - e dos outros - na tessitura de um sistema de aprendizagem colaborativa: algumas considerações teóricas}

Vygotsky (1978) diz que a Zona de Desenvolvimento Proximal (ZDP) é constituída de dois níveis de desenvolvimento. Um nível que ele denomina de desenvolvimento real e refere-se às conquistas já efetivadas pelo sujeito e outro, de desenvolvimento proximal, que neste caso, está relacionado com as capacidades em vias de serem construídas. Neste nível, para que tais capacidades se consolidem, o autor diz que é fundamental que o sujeito receba a ajuda de outras pessoas mais capazes, através dos processos de interação social. Assim, a questão que quero discutir aqui está relacionada à forma como Vygotsky advoga que esse processo se realiza nas estruturas cognitivas do sujeito, ou seja, como a aprendizagem (e o desenvolvimento humano) se efetiva sob a orientação ou em colaboração com pares mais capazes. A ZDP, torna-se preciso assinalar, é um conceito que Vygotsky formulou para mostrar e explicar como a aprendizagem social e participativa se processa e como ela vai conferindo ao sujeito o seu desenvolvimento cognitivo. Daniels (2003) observa que, apesar de Vygotsky não ter dedicado maior atenção a esse tópico em toda a sua extensa obra, o conceito de ZDP é frequentemente citado como uma das mais profundas contribuições para o debate pedagógico. É um conceito que, mesmo nebuloso, certamente moldou alguns aspectos do pensamento educacional e, por sua vez, foi moldado e apropriado por diferentes vozes no debate educacional.

Na descrição do conceito de ZDP, Vygotsky deixa explícito que o processo de aprendizagem pode ser operacionalizado de duas maneiras, ambas referem-se aos movimentos (ações de natureza pedagógicas) que 
os sujeitos (professor e alunos) realizam no contexto em que as práticas educacionais (presenciais/virtuais) se desenrolam. A primeira estabelece o papel da orientação instrucional. Uma ação que parece ser exercida basicamente pelo professor, uma vez que cabe a ele prescrever as maneiras sobre como a tarefa se organiza, o modo pelo qual os alunos devem executar as tarefas que lhe dizem respeito, enfim, as regras que indicam o modo apropriado com que os alunos devem agir para obterem sucesso (aprenderem) do que é deles requerido na tarefa. A orientação pressupõe uma trajetória planejada, ou seja, um ordenamento do sistema (redução dos fatos, conceitos, opiniōes, etc.), conformando-o dentro de um espaço determinado de tempo. É evidente que o sistema educacional não pode ser tomado numa perspectiva laissez-faire. Porém, é preciso reconhecer que mesmo sendo o processo educacional uma prática sistematizada, ela está sujeita à emergência de situações não previstas pelo professor e que, certamente, requerera dele uma reorganização do sistema.

A segunda possibilidade apontada por Vygotsky na operacionalização da ZDP, que de fato me interessa aqui, refere-se ao processo de colaboração exercida entre os pares envolvidos no processo de aprendizagem. Para o autor, a colaboração pode ajudar a desenvolver estratégias e habilidades gerais para a solução de problemas. A colaboração, do meu ponto de vista, deve ser entendida como uma propriedade das práticas educacionais, pois ela pode emergir espontaneamente ou ser provocada pelos agentes de um sistema de práticas educacionais. É uma questão que pode parecer paradoxal, pois, se por um lado este sistema pressupõe uma sistematização - padrão de organização - por outro, a colaboração, a exemplo de outros fatores imprevisíveis, pode interromper a ordem requerida pela orientação, já que ela pode desestabilizar aquilo que foi previamente estabelecido, ou seja, estruturado em uma ordem. Por esse motivo, torna-se muito mais pertinente pensarmos em restriçôes possibilitadoras, como sustenta Davis e Sumara (2006). Uma expressão que pode até sugerir uma contradição, pois reconhece que os sistemas sociais, caso da educação, por exemplo, são governados por normas - ordem instaurada - mas, sujeitas a eventos possibilitadores de emergências de situaçôes não previstas pelo professor.

Isso pode ocorrer na ZDP de cada sujeito, pois ela abriga um conjunto de conceitos e noções pré-construídos em seu nível real de desenvolvimento e são esses pré-construídos que fornecem as condições para que o sujeito possa ou não colaborar de forma efetiva uns com os outros. Trata-se, nos termos de Vygotsky, de um sujeito que possui um nível real de desenvolvimento maior, em decorrência 
do volume de conhecimentos aprendidos ao longo de sua trajetória de vida. Um conhecimento que está intrinsecamente ligado ao acúmulo de conceitos científicos e/ou cotidianos internalizados nas funções superiores de cada sujeitodimensão histórico-cultural. Vygotsky (1995) denomina de conceitos cotidianos (ou espontâneos) aqueles que são adquiridos pelo sujeito fora do contexto formal de aprendizagem (escola, universidade, etc.) ou de outra qualquer instrução informal e deliberada. Já os conceitos científicos seriam aqueles desenvolvidos no processo de assimilação de conhecimentos comunicados sistematicamente ao sujeito. Por isso, o conceito de ZDP, como observa Palincsar (1998), não pode ser retirado de sua estrutura teórica original e tomado apenas como ferramenta explanatória. Além disso, é preciso considerar o seu poder descritivo e evitar tomá-lo numa interpretação literal da ideia de capacidade. Em outras palavras, o conceito de ZDP deve ser tomado como uma gama de possibilidades (inclusive elementos da própria tarefa, o artefato cultural, etc.), que se colocam como presentes na mediação da aprendendizagem. A ZDP não se configura em um espaço de mera transmissão do sujeito que sabe para o que não sabe, mas que precisa conhecer. Em outros termos, trata-se de um processo não-linear de transmissão-aquisição de conhecimento e não uma mera relação de causa e efeito. Conforme observa Silva (2008), a ZDP, quando tomada com base em uma perspectiva complexa, ou seja, como o nexo de variáveis sociais, culturais e históricas, conduz, conforme argumenta Daniels (2003), a uma imagem para além do aluno solitário com o professor diretivo e determinante, pois fornece uma visão bem expandida do "social" e a possibilidade de uma concepção dialética da interação social.

O sujeito apresenta, independentemente se criança ou adulto, uma multiplicidade de coisas que ainda não consegue realizar sozinho. É a postura mediadora do outro, através dos instrumentos simbólicos e técnicos que podem possibilitar ao sujeito a apropriação do conhecimento necessário para que ele execute aquilo que é dele requerido. Essa apropriação não é passiva, pelo contrário, é tensa e contraditória (dialética) e isso é a evidência de que no processo da interação social, não existe, entre os pares, uma parte absolutamente mais capaz e nem, como pressuposição, uma menos capaz. O que determina a parte mais capaz na relação mediada são as condições de produção em que a tarefa se realiza. Um exemplo desta relação pode ser verificado no contexto das práticas pedagógicas da sala de aula da sociedade contemporânea, onde professores, em sua grande maioria, definitivamente sabem bem menos que os alunos nativos da era digital. Ou seja, em uma 
atividade pedagógica baseada no computador/internet em que professores e alunos, colaborativamente, trabalham juntos, é possível que a parte mais competente da relação, no que concerne aos conhecimentos sobre o uso da tecnologia, esteja entre os alunos.

A colaboração oferece as condições para que os pares e os grupos de pessoas compartilhem opinióes, dúvidas, problemas, autoridades, responsabilidades, etc., e juntas negociem formas de interpretação, resolução de problemas, cheguem a objetivos preestabelecidos e, principalmente, formulem e internalizem conceitos culturais espontâneos ou científicos. Frente a essas questões, adoto, no lugar de par mais capaz/par menos capaz, a expressão competências distribuidas. A adoção desta expressão encontra-se sustentada no entendimento de que ela abarca a questão do outro como mediador das práticas colaborativas educacionais e assegura a imagem de um sistema dinâmico, pois as posições dos sujeitos se alternam e são dependes do que cada sujeito da interação social possui de conhecimento real sobre a tarefa que está sendo desenvolvida. Ou seja, trata-se de uma relação sem a fixidez de nenhuma das partes sobre a outra, mas sim de um processo marcado por uma dinâmica de alternâncias randômicas e colaborativas entre os sujeitos que estão interagindo.

Uma melhor compreensão desse processo pode ser obtida através dos conceitos de diversidade (HOLLAND, 1995, VAN LIER, 2004) e de redundância (DAVID e SUMARA, 2006), tomados de empréstimo da biologia, para explicar a complexidade e o comportamento dos Sistemas Adaptativos Complexos (SACs). Na definição de Holland (1995), os SACs referem-se aos sistemas que são capazes de se autoconfigurarem para se adaptarem às características correntes do processo ou do ambiente em que estão inseridos, ou seja, configuram-se sistemas que atingem a solução, através de sucessivos ajustes e interaçôes dos agentes com o problema. É uma categoria de sistema que permite ver, com maior nitidez, como um processo colaborativo de aprendizagem se organiza. Nos SACs torna-se contraditória a vigência da dinâmica centralizadora e hierarquizada, logo, não se tem apenas um par mais capaz, mas sim, um conjunto, em sua totalidade sistêmica, em que todos podem se apresentar aptos para contribuir na solução de um problema e assim, dinamizar este sistema em toda a sua complexidade.

Um SAC é marcado pela sua diversidade, que no caso desse estudo, conforme apontado anteriormente, diz respeito, entre outros fatores biopsico-sócio-culturais, aos diferentes níveis de desenvolvimento real das ZDPs de cada sujeito que integra o sistema de um curso, por exemplo, e que, em 
seus processos de interação com os demais sujeitos, provoca a evolução e a complexidade do sistema como um todo. Nesse sentido, não importa qual o nível de desenvolvimento real de cada sujeito, pois, por menor que seja em comparação com os demais, cada sujeito se apresenta potencialmente apto para colaborar com a aprendizagem do outro em algum momento do processo, ou seja, ele também tem uma parcela de contribuição na e para a dinâmica do sistema, tanto em suas partes, como em seu todo.

Quanto maior a diversidade do ambiente colaborativo de aprendizagem, maiores são as chances de o sistema possuir redundância, em sua dinâmica. A redundância, conforme apontam Davis e Sumara (2006), refere-se à capacidade dos sujeitos, enquanto agentes do sistema, de substituírem funcionalmente o outro em situações de desestabilização do sistema, ou seja, um dos sujeitos assume, ainda que momentaneamente, a dianteira do processo e podem com isso "estabilizar" o sistema. Trata-se de uma assunção espontânea e, portanto, imprevisível, como mecanismo de manutenção da estabilidade do sistema. Com base nessa discussão, podemos dizer que um SAC abriga no seu interior uma inteligência distribuída que, conforme advoga Levy (1998), configura-se em "uma inteligência distribuída por toda parte do sistema, incessantemente valorizada, coordenada em tempo real, que resulta em uma mobilização efetiva das competências".

Esse entendimento sobre a redundância reforça os argumentos de Erickon (1996), quando diz que a maioria dos trabalhos em que o conceito de ZDP é aplicado se dá em cenários binários com um único perito e um único novato. Para ele, essa forma de relação não caracteriza os padrões de comunicação em situações de aprendizagem.

[...] professores e alunos interagem nas salas de aulas, constroem uma ecologia de relaçōes sociais e cognitivas em que a influência entre todas e quaisquer partes é mútua, simultânea e contínua. Um aspecto dessa ecologia social e cognitiva é o caráter multipartidário da cena - muitos participantes, todos eles "em cena" contínua, apesar de trabalharem em diferentes tipos de tarefas, algumas vezes conflitantes entre si. Embora os professores em discussóes em grupo possam tentar implementar uma estrutura participativa de sucessivas trocas didáticas professor-aluno, a conversação é amiúde mais complicada que isso (ERICKSON, 1996, p. 33)

Para ilustrar estas minhas reflexões sobre o papel do outro dentro de um sistema de práticas sociais de aprendizagem, que se sustenta por uma dinâmica de interação social baseada em competências distribuídas em detrimento das 
relações unidirecionais entre par mais capaz/menos capaz, trago para análise algumas situações que tipificam o processo dinâmico - complexo - de interação social realizada entre professor/alunos e aluno/aluno em uma comunidade baseada na internet (Lista de Discussão) denominada COMPSLA ${ }^{1}$, constituída por alunos de pós-graduação - mestrado e doutorado - matriculados em uma disciplina on-line do curso de doutorado do Programa de Pós-Graduação em Estudos Linguísticos (PosLin) da Faculdade de Letras (FALE) da Universidade Federal de Minas Gerais (UFMG).

\section{Diversidade/redundância e competências distribuídas na co- munidade COMPSLA}

Com o propósito de ilustrar a dinâmica dos pares da comunidade COMPSLA ao longo de sua trajetória temporal, elaborei o gráfico abaixo (Gráfico 1). Trata-se de uma representação visual que, do meu ponto de vista, pode contribuir para uma melhor compreensão da complexidade das práticas sociais desenroladas pelos pares da referida comunidade.

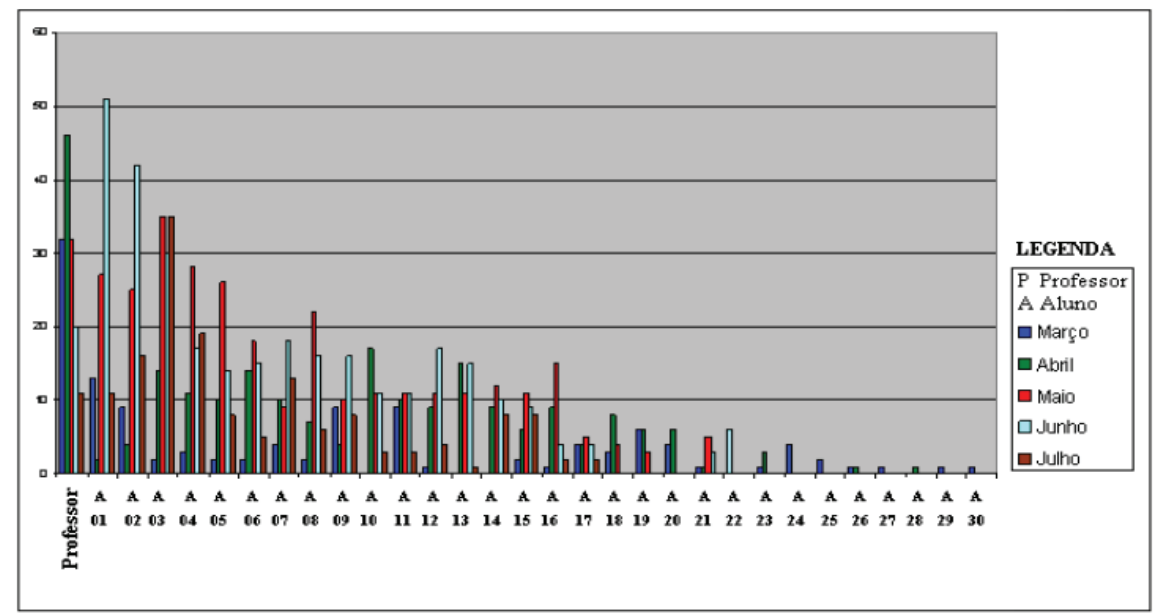

GRÁFICO 1

Fonte: SILVA (2008, p. 155)

\footnotetext{
${ }^{1}$ Sigla proposta pelo proponente do curso para a disciplina Seminário de Tópico Variável de Linguística Aplicada: Aprendizagem mediada pelo computador e teorias de aquisição de línguas estrangeiras.
} 
$\mathrm{Na}$ base do gráfico, encontram-se dispostos os 31 participantes (Professor e A - alunos) da comunidade, inclusive dos desistentes, e, sobre estes, eleva-se um grupo de 5 colunas com diferentes cores, uma para cada um dos 5 meses de duração do curso, conforme especificação na legenda todos os nomes que aparecem ao longo do texto são fictícios. Estas colunas indicam também o número de mensagens postadas na Lista de Discussão pelos participantes e o grau de interação dentro da comunidade. Para a elaboração desse gráfico, optei em disponibilizar os participantes em ordem decrescente, da esquerda para a direita, mostrando os que mais postaram mensagens e os que menos postaram.

A leitura do gráfico permite perceber que, nos 12 dias do mês de março (em azul), o participante que mais enviou mensagens, comparado com os demais, foi o Prof. Roberto. É um desempenho compreensível, pois corresponde ao período em que ele apresentou esclarecimentos sobre o programa do curso, fez as primeiras proposiçôes para discussão e tirou dúvidas dos alunos. Esse mesmo desempenho do professor também se verifica no mês de abril (em verde) e está marcado por publicações de emissivas relacionadas com os as discussóes teóricas propostas, mas principalmente por mensagens com o propósito de organizar os grupos de seminários previstos para o curso. Se, por um lado, o Prof. Roberto é o participante que se apresenta mais visível no referido período, por outro, é possível perceber que nos 3 últimos meses do curso, sua participação, ainda que expressiva no mês de maio, começa a declinar, tornando-o um par mitigado entre os demais participantes da comunidade, ou seja, apresenta um padrão de publicação de emissivas que pouco se discrepa da maioria dos outros participantes. É oportuno observar que esse reposicionamento do professor pode também estar relacionado com a realização dos seminários conduzidos pelos próprios alunos. Porém, isso não quer dizer que o professor não estivesse acompanhando a discussão, pelo contrário, sugere que suas interferências foram suplantadas pelo coletivo dos alunos dentro da comunidade: pelas inteligências e competências distribuidas na comunidade. Esses argumentos se encontram respaldados nas próprias palavras do Prof. Roberto. Veja o que ele diz:

\section{Excerto \# 1}

No início do curso minha percepção é de que eu tinha que supervisionar muito os participantes para que a dinâmica que eu tinha idealizado para o funcionamento do mesmo de fato ocorresse. Havia muitas 
dúvidas, havia a participação de pessoas que na época não tinham ainda experiências com cursos similares. Eu sentia que tinha que me fazer muito presente para que fosse criada a "cultura" de funcionamento que eu via como interessante para o trabalho. À medida que as coisas começaram a funcionar bem, comecei a achar que na verdade não valia muito a pena eu me fazer constantemente presente, pois eu sentia que de certa maneira um posicionamento meu acerca de um tópico de discussão, por exemplo, acabava por encerrar uma discussão entre os participantes que ainda poderia ter uma vida maior. Prof. Roberto (em questionário de 18/01/08).

Esse reposicionamento do professor contribuiu para que outros pares do sistema também se reposicionassem, indicando, assim, o aspecto da diversidade que caracteriza o sistema, em decorrência de suas múltiplas competências que nele vicejou durante todo o tempo. É extremamente significativo também o reconhecimento do professor de que a diversidade e as competências dos participantes contribuíram para a constituição e manutenção de uma comunidade de práticas sociais de aprendizagem desfocada do professor. Um reconhecimento que permite afirmar que a comunidade em questão teve de fato uma cultura sustentada pelo princípio da colaboração e governada por uma inteligência coletiva.

Ainda de acordo com o Gráfico 01, à medida que a participação do professor declina, começa a ganhar visibilidade a participação de alguns alunos, como é o caso de Ana, seguido por Jorge e, este, por Luiz Paulo, o recordista em número de publicações de emissivas na comunidade COMPSLA. São casos que apontam para um desempenho bastante satisfatório, pois suas atuaçóes destoam dos demais alunos que também foram responsáveis por tal tarefa. São situações que apontam a existência de uma competência distribuída no sistema e que corroboram com os argumentos de Holland (1995) e van Lier (2004) quando referem-se à diversidade de um Sistema Adaptativo Complexo.

A emergência da colaboração, para além daquele que se encontra legitimado institucionalmente (o professor), se configura em uma propriedade dos processos de interação sócio-pedagógicos, que surge espontaneamenteao acaso - dentro do sistema, em decorrência da percepção dos outros sobre a competência de alguns, como é o caso, por exemplo, dos alunos Jorge e Luiz Paulo. Ou seja, está relacionado, no caso do curso, com a capacidade dos mesmos em compreender aquilo que está sendo requerido na tarefa, tais como, capacidade de interpretar as proposiçôes teóricas defendidas 
pelos autores estudados; de perceber os equívocos teóricos dos colegas; na capacidade de redimensionar aspectos que poderiam passar despercebidos; etc. Como podemos verificar nos exemplos acima, no sistema do curso havia uma descentralização do professor, pois ele mesmo estava sujeito à redundância Davis e Sumara (2006), ou seja, nos termos de Vygotsky, o professor deixa de se constituir a parte mais competente dos pares. Vejamos esse funcionamento no gráfico abaixo, que marca o movimento do professor ao longo do curso.

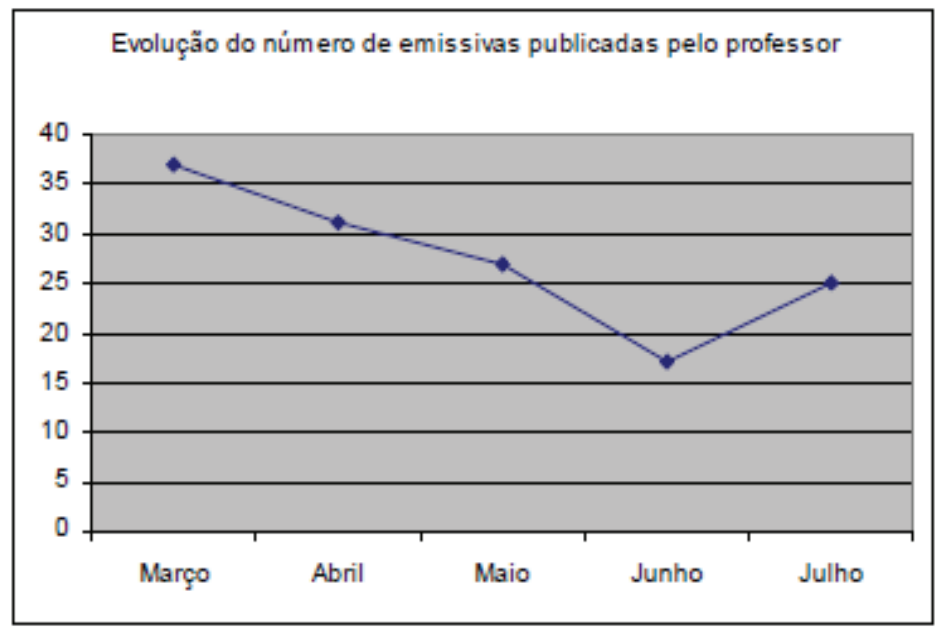

GRÁFICO 2

Fonte: SILVA (2008, p.158)

O gráfico aponta o número de mensagens enviadas pelo professor e, através dele, é possível perceber a existência de uma ordem decrescente na publicação das emissivas. No mês de março e julho, constata-se a incidência de um grande volume de emissivas publicadas pelo professor e, como já apontado, refere-se ao início e final do curso, ou seja, as duas situações em que ele precisou, no primeiro momento, encaminhar os procedimentos de abertura do curso e no segundo, os encaminhamentos de encerramento. Porém, nos meses de abril, maio e junho ele apresenta uma atuação decrescente na publicação de suas emissivas. É uma situação que reforça os meus argumentos sobre competência distribuída, evidenciada tanto no comentário da aluna Laura (excerto \# 2) quanto na observação feita pelo próprio Prof. Roberto (excerto \# 3). 


\section{Excerto \# 2}

Raramente pedimos a participação efetiva do Roberto (e até nos referimos a ele na terceira pessoa!!!). Analisando, as intervençôes dele, elas eram mais frequentes no início do curso e agora, como ele mesmo apontou, os alunos é que "mediam" a interação. Laura (E-mail: 17/06/2004).

\section{Excerto \# 3}

Plena verdade, não? Nossa comunidade de aprendizagem já há algum tempo ganhou vida própria. Para mim, nada poderia ser tão satisfatório! Prof. Roberto (E-mail: 17/06/2004).

Um exemplo dessa competência distribuída, que caracteriza o processo de redundância no sistema, como defende David e Sumara (2006), pode ser verificado nos excertos abaixo. Esse processo inicia-se quando o aluno Jorge, com a finalidade de elaborar o trabalho final do curso, solicita ao professor informações sobre como acessar as mensagens que estão arquivadas na página do curso, ou seja, no sistema do Yahoo!Groups. Antecipando-se ao professor, a aluna Marisa responde:

\section{Excerto \# 4}

[...] Você consegue acessar as mensagens já enviadas através desse endereço mesmo. É só logar no yahoo. [...]. Marisa (e-mail: 05/07/04)

$\mathrm{Na}$ sequência, de acordo com o excerto \# 5, o professor também responde à pergunta de Jorge:

\section{Excerto \# 5}

[...] Pode sim. Basta você entrar. Confira se você está registrado na página. Se não estiver, basta fazê-lo. O procedimento baseia-se no fornecimento de dados de identificação e é automático. [...]. Roberto (e-mail: 05/07/04)

Porém, o aluno, dirigindo-se ao Professor e à colega Marisa, através do excerto \# 6, reafirma suas dificuldades: 


\section{Excerto \# 6}

Não consigo acesso. Aparece uma mensagem dizendo que eu não sou membro do grupo (embora apareçam meus 2 endereços eletrônicos lá). Olhem a mensagem que aparece: You are not a member of the group compsla. If you believe you are a member, Find your membership Quando tento entrar no link, nada acontece! Estranho! Vou continuar tentando. Jorge (e-mail: 05/07/04)

Mediante esse relato e percebendo a necessidade de melhor especificar os passos que Jorge deveria realizar para atingir o seu objetivo, Marisa produz uma nova mensagem, apontando como ele pode atingir os seus propósitos. Ou seja, ela produz uma descrição das etapas que Jorge deve seguir ou, dito de outra forma, Marisa aciona um dinamizador (SILVA, 2008) para facilitar a relação de colaboração.

\section{Excerto \# 7}

[...] No alto da página http://groups.yahoo.com/group/compsla/ clique em Sign in. Aí você fornece seu username e senha. Depois, no canto esquerdo da tela clique em my groups, compsla. O link para mensagens estará disponível. Marisa (e-mail: 06/07/04)

Ainda no contexto de colaboração do professor Roberto e de Marisa com Jorge, percebe-se que o processo colaborativo não se limita a esta tríade de interação, pois há, conforme é possível de se verificar no Excerto \#8, a participação de um quarto colaborador, o aluno Luiz Paulo que provê a Jorge a seguinte orientação:

\section{Excerto \# 8}

Você tem um e-mail yahoo? Se você tiver, peça o prof. Roberto para cadastrá-lo no grupo. Feito isso, é só acessar a página do yahoo, clicar em grupos e inserir seu login e senha. Eu nunca tentei acessar as mensagens sem logar no sistema, então nunca tive problema. Não sei se é esse o caso, mas não custa tentar. Luiz Paulo Carlos (e-mail 06/07/04)

É possível depreender dessa dinâmica colaborativa, que ela se inicia com uma emissiva postada por Jorge com um pedido de ajuda ao Prof. Roberto. Nesse processo, tal emissiva funcionou, ao mesmo tempo, como um dinamizador do sistema (SILVA, 2008) como um todo e também como um 
dinamizador da colaboração, pois provocou a entrada espontânea de outros na discussão. Tem-se nesse caso, um aspecto marcado pela previsibilidade - a resposta, por parte do Prof. Roberto, esperada por Jorge - mas também, pela imprevisibilidade expressa nas mensagens de Marisa e Luiz Paulo. Ou seja, temos um processo que rompe com o caráter diretivo da relação professor/ aluno e assume novos contornos, em decorrência das características do próprio sistema, como já apontado anteriormente. Uma evidência dos efeitos dessa colaboração para a aprendizagem de Jorge sobre o problema técnico que ele apresentou ao grupo é fornecida por ele mesmo em um trecho do texto de avaliação do curso:

\section{Excerto \# 9}

[...] recebi ajuda dos mais variados tipos, incluindo questóes técnicas sobre ter acesso às informações no site do curso na WWW. Jorge (em 13/07/04).

Como é possível de se verificar, todo esse movimento de colaboração em torno do problema técnico apresentado pelo aluno Jorge ilustra como a díade par mais capaz (o professor) e parte menos capaz (alunos) não se efetivou em várias situações, reforçando a minha proposição para aquilo que optei em denominar de competências distribuidas. Embora fosse o professor o sujeito que, institucional e hierarquicamente, se apresentava como o mais capaz, foi possível perceber que, ao longo das discussões, determinados alunos apresentavam suas competências, de maneira espontânea e imprevisível, ao ponto de essa posição não ser somente reconhecida pelos demais alunos, mas também pelo próprio professor. Havia, assim, por parte dos participantes, um reconhecimento, ainda que temporário, das contribuiçôes dos alunos que colocavam suas competências em distribuição, apontando assim, a diversidade do sistema. Esse funcionamento ficou tão evidente que, em várias situaçôes, os demais alunos se dirigiam àquele aluno, como se ele fosse, nas palavras de Vygotsky, a parte mais capaz, mais competente na discussão do assunto que se encontrava em debate. Trata-se, portanto, de uma situação que rompe com a interação diretiva entre professor-aluno para se constituir em outra direção, ou seja, o saber e o poder são moventes e derivam para cada um dos integrantes do sistema que queiram colocar em distribuição suas competências com os demais sujeitos que se inscrevem no sistema do curso. A emergência de estados de colaboração, por parte do outro que apresenta maior competência dentro do contexto por mim estudado, é também um indicativo do 
quanto o processo de aprendizagem, dentro de uma abordagem compartilhada, é imprevisível. Esses meus argumentos podem ser verificados nos dois trechos extraídos do questionário respondido pelas alunas Eliane e Climene:

\section{Excerto \# 10}

Não dá pra esquecer que passamos nossa vida estudantil quase toda no ambiente da sala de aula e, portanto, nossa crença de que o professor deve "amarrar" as discussōes esteve presente sim. Senti essa necessidade e o professor Roberto fez isso muito bem várias vezes, se bem que o Jorge e o Luiz Paulo também esclareciam ou resumiam alguns dos temas, exercendo dessa forma esse papel. Eliane (Questionário: 17/07/04)

\section{Excerto \# 11}

O professor estimulou, questionou, valorizou a contribuição de cada um, não se colocando acima dos alunos como detentor do conhecimento. $\mathrm{Na}$ maioria das vezes, os próprios colegas é que respondiam as dúvidas dos outros e não o professor. O papel dele foi o de facilitador do processo. Climene (Questionário: 20/07/04)

É interessante observar que o distanciamento das discussões assumido pelo Prof. Roberto, diferentemente do ocorrido no início do curso, favoreceu naturalmente a emergência de outras competências dentro do sistema. Ele deixa de produzir mensagens que, em sua maioria, funcionavam como dinamizadores do sistema, através, por exemplo, de uma problematização teórica, de uma pergunta, etc.

$\mathrm{Na}$ discussão conduzida sobre competências distribuídas, tornase importante marcar que o processo de aprendizagem, baseado na perspectiva complexa, a partir do CAS, não pode se assentar apenas no desempenho do número de emissivas publicadas por um sujeito, pelo contrário, precisa considerar também que, mesmo com um baixo número de emissivas, um sujeito pode estar participando do curso e distribuindo suas competências. Assim, não considerar o papel desses sujeitos para a dinâmica do sistema é entrar em contradição com os próprios postulados das teorias da complexidade, pois, por menor que sejam suas participações, o que esses sujeitos produzem em suas interaçóes alimenta o sistema e pode se configurar em condições iniciais que podem mudar a trajetória do sistema.

No Gráfico 03, a diferença do número de mensagens enviadas pelos alunos Luiz Paulo (147 mensagens) e Jorge (60 mensagens), respectivamente, 
os dois que mais participaram e contribuíram para a dinâmica do grupo, é visivelmente superior às dos alunos Rafael (29 mensagens) e Laura (25 mensagens), os dois alunos que menos postaram mensagens ao longo do curso.

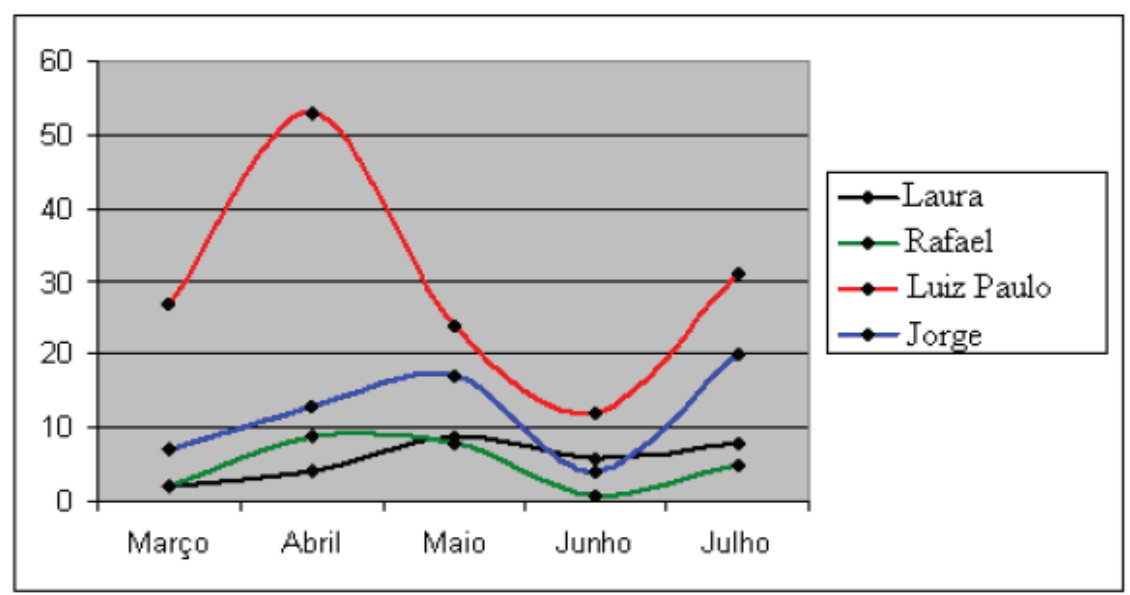

\section{GRÁFICO 3}

Fonte: SILVA (2008, p. 160)

Essa diferença, contudo, não pode ser tomada como critério para dizer que esses alunos não contribuíram para a dinâmica do sistema do curso e nem que não aprenderam. Pelo contrário, eles também trouxeram contribuições significativas para o grupo, pois suas mensagens também dinamizaram o sistema. Para ilustrar o que digo, apresento os seguintes excertos. No primeiro caso (excerto \# 12), temos a mensagem do aluno Rafael em que diz:

\section{Excerto \# 12}

[...] Acho que é relevante fazer um divisor de águas uma vez que as expectativas de um podem não ser as mesmas no outro. Por exemplo, qual seria, para um aluno, a carga de exposição ideal da língua-alvo. Claramente, se o estudo da língua se dá num país como o nosso, a exposição será bem menor do que num país onde a língua-alvo é falada. Outro fator é a "qualidade" desta exposição que muitas vezes, no nosso caso, se dá em condições de ambiente artificiais. Esta divisão também deve ser considerada em atividades de CALL? Rafael (e-mail: 13/04/04). 
Como resultado da mensagem postada por Rafael, veja o que diz o Prof. Roberto:

\section{Excerto \# 13}

Considero as indagações do Rafael de extrema relevância e, em última análise, articuladas com as consideraçōes e críticas trazidas por Jorge ontem acerca do contexto de produção da pesquisa de Ehrman e Leaver. Gostaria muito de estimulá-los a comungarem conosco percepções que vocês porventura tenham sobre este tema. Aguardo suas reflexôes. Prof. Roberto (e-mail: 14/04/04).

Como observado anteriormente, em ambos os casos, mesmo tendo Laura e Rafael apresentado uma participação menor quando comparados com a de Luiz Paulo e Jorge (Gráfico 3), torna-se importante observar que suas mensagens desempenharam um papel importante para a dinâmica do grupo como um todo. Por exemplo, veja o que a aluna Laura diz:

\section{Excerto \# 14}

[...] No início, esperava que o curso fosse como os que eu havia participado anteriormente, mas este superou minhas expectativas. $\mathrm{O}$ grupo se entrosou tão bem que todos se superaram. Meu desempenho poderia ter sido melhor em relação às participaçōes, mas acredito que isso seja da minha própria natureza. Em alguns tópicos os quais não me interessam tanto quanto outros (sobre conexionismo, por exemplo) fiz o mínimo exigido. [...] Laura (em questionário de 26/07/04).

Como podemos verificar, trata-se de uma situação que ilustra, em certa medida, que a baixa interação dos dois alunos em questão, não os apaga no sistema, eles são agentes com potencial de participação que pode, por exemplo, em um determinado momento desencadear diferentes níveis de dinâmica dentro do sistema.

\section{Conclusão}

Como foi possível verificar, no contexto da comunidade COMPSLA, o processo de colaboração não se traduziu com base em uma relação unidirecional, pelo contrário, explicitou-se em um processo mutidirecional, em que os pares compartilharam opiniōes, dúvidas, problemas, autoridades, 
responsabilidades, etc., e juntos negociaram formas de interpretação, resolução de problemas, chegaram a objetivos preestabelecidos, etc. São essas características que me conduziram a adotar no lugar de par mais capaz/menos capaz do conceito de ZDP, o conceito de colaboração e competências distribuidas, uma vez que todos os pares se apresentavam aptos para colaborarem uns com os outros, independentemente de seus níveis de conhecimento. É uma perspectiva que corrobora também a reflexão de Paiva (2010) que, com base em narrativas sobre aprendizagem de língua Inglesa, aponta uma situação em que um sujeito tido como menos capaz, contribuiu para a dinamicidade do processo de aquisição. Para ela, aprender a falar uma língua estrangeira, implica, necessariamente, usar essa língua, e essa é uma atividade que se realiza com o outro e não, necessariamente, com um par mais competente.

No sistema do COMPSLA, não houve uma fixidez de nenhuma das partes dos pares, mas sim, uma dinâmica de alternância randômica de posições colaborativas entre eles. Em outras palavras, o sistema da comunidade, em função de sua diversidade (HOLLAND, 1995; VAN LIER, 2006) apresentou um auto grau de redundância (DAVID e SUMARA, 2006), configurando-o em um típico Sistema Adaptativo Complexo (SACs) que, conforme define Holland (1995), caracteriza os sistemas que têm a capacidade de se auto-configurarem e se adaptarem às necessidade requeridas pelo sistema em seu todo, em decorrência das interações realizadas entre os agentes, no caso deste trabalho, os participantes do grupo.

Percebe-se ainda que a construção de um modelo de práticas pedagógicas ancorado na perspectiva colaborativa de construção de conhecimento, seja na modalidade presencial, semipresencial ou a distância está calcado não apenas no design de um curso, mas também na atitude colaborativa dos pares que agem dentro do sistema. É uma questão que requer uma mudança cultural na forma sistêmica como se ensina e aprende, pois partes - cada sujeito - e o todo - coletivos destes sujeitos - estão articulados, conformando sistemas em que não há nem o periférico e nem o central. É enfim, reconhecer que, definitivamente, há uma inteligência extraordinariamente coletiva e distribuída que opera em todos os níveis para manter a dinamicidade do sistema sempre vívida e pronta para possibilitar a emergência de novos conhecimentos, tanto na ZDP de cada sujeito, como no coletivo das ZPDs dos sujeitos, estejam eles inseridos em um sistema social real ou virtual. Definitivamente, nada mais plausível de se admitir para as práticas sociais do mundo contemporâneo. 


\section{Referências}

DANIELS, H.. Vygotsky e a pedagogia. Edições Loyola. Sao Paulo. 2003.

DAVIS, B. e SUMARA, D. Complexity and education: inquires into learning, teaching, and research. Mahwah, New Jersey e London, Lawrence Erlbaum Associates. 2006.

ERICKSON, F. Going for the zone: the social and cognitive ecology of teacherstudent interaction in classrooms conversations. In D. H. (Ed.) (1996) Discourse, Learning, and Schooling: 29-62. Cambridge, MA: C.U.P. 1996

HOLLAND, J. H. Hidden Ordem: how adaptation builds complexity. Perseus books, Cambridge, Massachusetts, 1995.

LÉVY, P. A Inteligência Coletiva por uma antropologia do ciberespaço. São Paulo: Ediçốes Loyola, 1998.

PAIVA, V.L.M. O. O outro na aprendizagem de línguas. In: HERMONT, A.B.; ESPÍRITO SANO, R.S.; CAVALACANTE, S.M.S. Linguagem e cognição: diferentes perspectivas, de cada lugar um outro olhar. Belo Horizonte: Editora PUCMINAS, p.203-217, 2010.

PALINCSAR, A. S. Keeping the Metaphor of Scaffolding FreshA Response to C. Addison Stone's "The Metaphor of Scaffolding: Its Utility for the Field of Learning Disabilities". In: Journal of Learning Disabilities. 7/1/1998.

SILVA, V. Interação social e estratégias lingüisticas no processo de provimento de andaime - scaffolding - em uma disciplina de Bioquímica da Nutrição oferecida a distância via computador. (Dissertação de Mestrado DLA/IEL) - Campinas, SP: [s.n.], 2003.

SILVA, V. A Dinâmica Caleidoscópica do Processo de Aprendizagem Colaborativa no Contexto Virtual: um estudo na perspectiva da Complexidade/Caos. ESTUDO NAPERSPECTIVA DA COMPLEXIDADE/CAOS. 2008. 237 F. Tese (Doutorado em Estudos Linguísticos) - Faculdade de Letras, Universidade Federal de Minas Gerais, Belo Horizonte, 2008.

SILVA, V. O conceito de Zona de Desenvolvimento Proximal (ZDP) na perspectiva da teoria da complexidade e do caos: uma releitura. In: Sistemas adaptativos complexos: lingua(gem) e aprendizagem. PAIVA, V. L. M. de O. e NASCIMENTO, M. do (Orgs.). Belo Horizonte: Faculdade de Letras da UFMG, 2009. 269 p. VAN LIER, L. The ecology and semiotics of language learning: a sociocultural perspective. Kluwer Academic Publishers. 2004

VYGOTSKY, L. S. Obras escogidas III: problemas del desarrollo de la psique. Visor. Madri. España. 1995.

VYGOTSKY, L. S. Mind and Society: The development of higher psychological process. Harvard University Press. Cambridge, Massachusetts. 1978.

Data de submissão: 12/11/2014. Data de aprovação: 11/02/2015. 